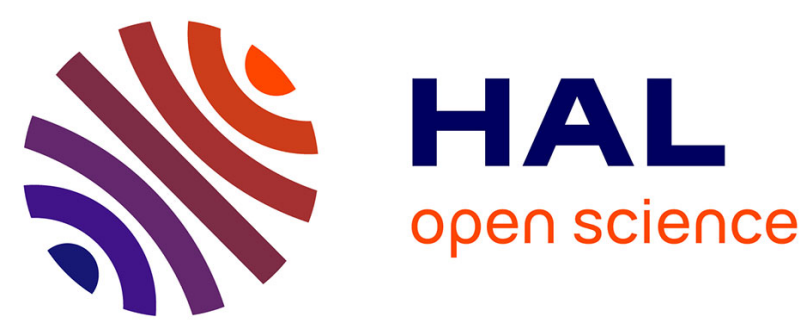

\title{
High absolute bioavailability of methylene blue given as an aqueous oral formulation
}

\author{
Ingeborg Walter-Sack, Jens Rengelshausen, Heike Oberwittler, Juergen \\ Burhenne, Olaf Mueller, Peter Meissner, Gerd Mikus
}

\section{- To cite this version:}

Ingeborg Walter-Sack, Jens Rengelshausen, Heike Oberwittler, Juergen Burhenne, Olaf Mueller, et al.. High absolute bioavailability of methylene blue given as an aqueous oral formulation. European Journal of Clinical Pharmacology, 2008, 65 (2), pp.179-189. 10.1007/s00228-008-0563-x . hal-00477926

\section{HAL Id: hal-00477926 \\ https://hal.science/hal-00477926}

Submitted on 30 Apr 2010

HAL is a multi-disciplinary open access archive for the deposit and dissemination of scientific research documents, whether they are published or not. The documents may come from teaching and research institutions in France or abroad, or from public or private research centers.
L'archive ouverte pluridisciplinaire HAL, est destinée au dépôt et à la diffusion de documents scientifiques de niveau recherche, publiés ou non, émanant des établissements d'enseignement et de recherche français ou étrangers, des laboratoires publics ou privés. 


\title{
High absolute bioavailability of methylene blue given as an aqueous oral formulation
}

\author{
Ingeborg Walter-Sack • Jens Rengelshausen • \\ Heike Oberwittler • Juergen Burhenne • Olaf Mueller • \\ Peter Meissner • Gerd Mikus
}

Received: 10 July 2008 / Accepted: 27 August 2008 / Published online: 23 September 2008

(C) Springer-Verlag 2008

\begin{abstract}
Purpose Methylene blue (MB) has recently been reevaluated for malaria treatment. With the aim of excluding treatment failures due to low bioavailability, we have investigated the absolute bioavailability of MB given as an aqueous oral formulation and its interaction with chloroquine (CQ).

Methods A phase I study in 16 healthy individuals was performed as a monocenter prospective open randomized
\end{abstract}

I. Walter-Sack $\cdot$ J. Rengelshausen $\cdot$ H. Oberwittler $\cdot$ J. Burhenne $\cdot$

G. Mikus $(\bowtie)$

Department of Internal Medicine VI,

Clinical Pharmacology and Pharmacoepidemiology,

University Hospital,

Im Neuenheimer Feld 410,

69120 Heidelberg, Germany

e-mail: gerd.mikus@med.uni-heidelberg.de

O. Mueller $\cdot$ P. Meissner

Department of Tropical Hygiene and Public Health,

Ruprecht-Karls-University,

Heidelberg, Germany

Present address:

J. Rengelshausen

Arensgasse 4a,

52078 Aachen, Germany

Present address:

H. Oberwittler

34 Boulevard de Grenelle,

Paris, France

Present address:

P. Meissner

Department of Paediatrics,

Department of Tropical Hygiene and Public Health,

AIC Kijabe Hospital of Eldoret University,

Eldoret, Kenya intra-individual cross-over comparison of MB single doses [50 mg intravenous (i.v.), $500 \mathrm{mg}$ orally, separated by a 1week wash-out]. After a second week, the group was split for a randomized parallel group comparison of CQ $750 \mathrm{mg}$ administered orally alone or combined with $500 \mathrm{mg}$ MB orally.

Results Mean $\mathrm{MB}$ plasma area under the substrate concentration-time curve $\left(\mathrm{AUC}_{0-\infty}\right)$ was 7,639 $\pm 3,384 \mathrm{ng} /$ $\mathrm{mL}^{*} \mathrm{~h}$ and $51,171 \pm 17,147 \mathrm{ng} / \mathrm{mL}^{*} \mathrm{~h}$ after i.v. and oral administration, respectively (dosage 1:10), and 76,897士 $46,037 \mathrm{ng} / \mathrm{mL} * \mathrm{~h}$ after MB combined with CQ. The absolute bioavailability was $72.3 \pm 23.9 \%$. Co-administration with CQ significantly increased MB plasma concentrations $(p \leq 0.016)$; CQ kinetics remained unaffected.

Conclusion The absolute bioavailability of MB is high. Co-administration of MB and CQ increases plasma, but not whole blood MB concentrations.

Keywords Bioavailability Chloroquine $\cdot$ Kinetics .

Methylene blue

\section{Introduction}

Methylene blue (MB, methylthioninium chloride) has recently been reinvestigated for various aspects of its antimalarial activity, such as its selective inhibition of glutathione reductase of Plasmodium falciparum [2, 27], and MB-based combination therapy is currently under development for the treatment of uncomplicated malaria in Sub-Saharan Africa [17-19, 31]. Methylene blue was used more than a 100 years ago against malaria in children and adults in South America and Europe [7, 10, 14], but it was abandoned when other treatments became available. Apart from malaria, MB is still used for a number of other 
relevant indications, mainly for the treatment of methemoglobinemia and for the prevention and treatment of ifosfamide-induced encephalopathy in cancer chemotherapy $[1,16,23,32]$. Other applications of MB include visualization of target tissues during surgery [15], supportive treatment of anaphylactic reactions [9, 21], and pathogen inactivation in fresh frozen plasma $[25,28,30]$. It has even been reported to be beneficial against sepsis [5].

For systemic treatment regimens, MB can be administered orally and intravenously (i.v.). Following oral intake, in humans the drug is absorbed from the gastrointestinal tract, reaching maximum plasma concentrations after $1-2 \mathrm{~h}[24,26]$. Maximum whole blood MB concentrations after oral or i.v. administration of $100 \mathrm{mg}$ were observed to differ in the order of 1:100 [24]; a difference in the same order of magnitude was reported for $\mathrm{AUC}_{0-4 \mathrm{~h}}\left(9\right.$ vs. $\left.137 \mathrm{nmol} / \mathrm{mL}^{*} \mathrm{~min}\right)$. The plasma half-life was found to be about 5-6.5 h [24, 26]. Renal excretion of MB was, on average, $74 \%$ (range 53-97\%) after an oral dose of $10 \mathrm{mg}$ [4], and about $20-30 \%$ after of an oral dose of $100 \mathrm{mg}$ [24]. Data from animal studies showed that MB crosses the blood-brain barrier, with i.v. administration leading to much higher concentrations in the central nervous system than oral intake, indicating differences in organ distribution after oral and i.v. MB administration [24]. Such observations may at least in part explain why MB taken orally is reported to be safe in much higher doses than when it is given intravenously.

For safe oral drug administration in very young pediatric patients, especially those under the age of 2 years, it is essential to use liquid medicines [8]. This means that the recent development of $\mathrm{MB}$ for effective malaria treatment in African children has to include a liquid MB formulation. In order to exclude a low bioavailability of $\mathrm{MB}$ as a reason for potentially insufficient therapeutic effects, an assessment of oral bioavailability was required. The primary aim of this study was to determine the absolute bioavailability of MB when given as an aqueous oral formulation. A supplemental part of the study was linked to a bioavailability assessment evaluating chloroquine (CQ) and MB concentrations when using higher $\mathrm{MB}$ doses than those tested in our previous phase I study, which had indicated a slight decrease of CQ concentrations during the initial 24 $\mathrm{h}$ after co-administration of MB and CQ [26].

\section{Materials and methods}

Study design

This phase I study in 16 healthy individuals was performed as a monocenter prospective open randomized intraindividual cross-over comparison of single doses of $\mathrm{MB}$
(50 mg i.v., $500 \mathrm{mg}$ orally, study days 1 and 8 , separated by a washout phase of 1 week; Fig. 1, part A). After a further washout phase of 1 week, the group was split for a supplemental randomized parallel group comparison of CQ (single oral dose of $750 \mathrm{mg}$ ) given alone or combined with $500 \mathrm{mg}$ MB orally (study day 15; Fig. 1, part B). Because of the long elimination half-life of $\mathrm{CQ}$, it was not feasible to include the second part into the cross-over comparison. Venous blood samples were drawn up to $24 \mathrm{~h}$ (Fig. 1, part A) and 72 h (Fig. 1, part B). Since malaria parasites are mainly found in erythrocytes, whole blood MB concentrations in addition to plasma concentrations were analyzed in order to estimate MB within erythrocytes as the intended target tissue.

The study was carried out in accordance with the Declaration of Helsinki adopted by the World Medical Association in 1964, Version of Somerset West 1996 (according to physicians' professional law at the time of study conduction), further specific legal regulations in Germany (as required prior to implementation of the EU Directive 2001/20/EC into national law), and the Note of Guidance on Good Clinical Practice (CPMP/ICH/135/95). Written approval by the Ethics Committee of the Medical Faculty of the University of Heidelberg was obtained prior to beginning the study. Voluntarily signed informed consent after a full explanation of the study verbally and in writing was obtained from each participant prior to inclusion.

\section{Study drugs}

The aqueous liquid oral preparation of $\mathrm{MB}$ containing $25 \mathrm{mg} / \mathrm{mL}(2.5 \%)$ was supplied by Mayrhofer Pharmazeutika GmbH, Linz, Austria, (manufacturer) under contract of DSM Fine Chemicals Austria. It was part of the investigational study lot which was produced for bioavailability testing and a phase II study in African children [18]. For intravenous application, a commercially available MB formulation was used, purchased by the Hospital Pharmacy

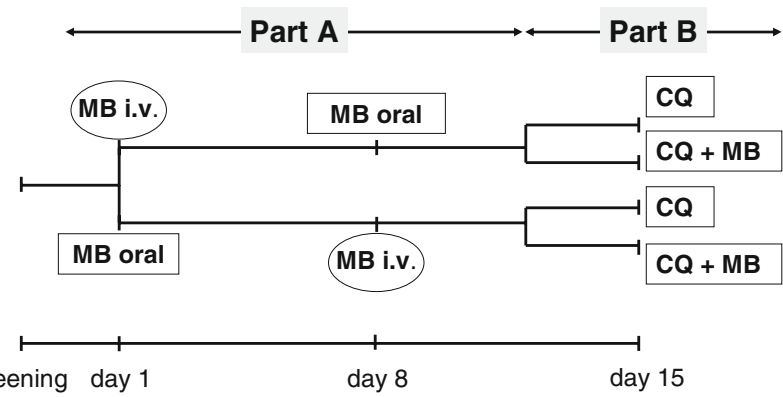

Fig. 1 Study design. Intra-individual cross-over of intravenous (i.v.) and oral methylene blue $(M B)$ administration (part $A$ ), followed by a parallel group comparison of $\mathrm{MB}$ alone and $\mathrm{MB}$ combined with chloroquine $(C Q)$ (part $B)$ 
(Methylenblau VITIS ${ }^{\circledR}$ ). The CQ tablets were also commercially available (CQ phosphate, Resochin ${ }^{\circledR}$ tablets $250 \mathrm{mg}$ ) and purchased by the hospital pharmacy.

\section{Study population and procedures}

Sixteen healthy individuals (nine males and seven females) were included in the study. Their mean age was $26.3 \pm$ 4.9 years, mean weight was $67.1 \pm 10.4 \mathrm{~kg}$, mean height was $173 \pm 7 \mathrm{~cm}$, and mean body mass index was $22.2 \pm 2.1$. Eligibility screening started in August 2004, and the last individual completed participation in October 2004. One participant (nr. 9) dropped out due to symptoms of a common cold prior to the second study day; another one (nr. 10) did not participate in part B because of a bicycle accident after completing part A.

Eligibility was based on an uneventful medical history, normal pre-study findings of a comprehensive physical examination, 12-lead electrocardiograph (ECG), safety clinical chemistry and hematology screening, determination of glucose-6-phosphate dehydrogenase (G6PD), urine analysis, and a qualitative pregnancy test in female participants performed within 3 weeks prior the first scheduled dosing of the study medication. Important exclusion criteria were renal insufficiency, G6PD deficiency, retinopathy, blood disorders, myasthenia gravis, epilepsy, psoriasis, allergies (except for mild forms of hay fever) or history of hypersensitivity reactions, pregnancy or lactation, as well as any other acute or chronic disorder that could interfere with the safety of the participants or the study objectives. Administration of any other investigational drug during the 2 months preceding study onset or other drug treatments necessary during the 4-week period prior to study onset also led to exclusion. This especially referred to treatments with a known inhibitor or inducer of drug-metabolizing enzymes or transport proteins within a period of less than ten times the respective elimination half-life. Co-administration of oral contraceptive drugs was permitted, but changes in usage were not allowed during the study. If intermittent drug treatment was necessary, the investigator could decide whether this was acceptable for participation in the study or whether the individual needed to be excluded for aspects of his or her own safety or for aspects of reliability of the data. In addition, smoking, excessive drinking of alcoholic beverages (more than approximately $30 \mathrm{~g}$ alcohol/day), drug addiction or a positive result in urinary drug screening, excessive coffee drinking (more than six cups per day), excessive physical activities during the days prior to the study, and blood donation within the last 2 months were reasons for exclusion.

Upon admission on the first study day, the individual was not included if there was any doubt about the status of unimpaired health. In female participants, a qualitative pregnancy test was performed and analyzed before drug administration on study days 1,8 , and 15 and, additionally, a plasma sample was analyzed for $\beta$-human chorionic gonadotropin. A post-study follow-up examination was scheduled within 8-14 days after the last pharmacokinetic blood sampling to verify the health of the participant.

The randomization list was prepared by computer generation (http://www.randomization.com). Participants were allocated to the numbers in chronological order. An individual drug treatment regimen had been predefined for each participant number (bioavailability assessment: randomized order of i.v. and oral preparation of $\mathrm{MB}$; subsequent study part B: randomized assignment of participants to $\mathrm{CQ}$ alone or combined $\mathrm{MB}-\mathrm{CQ}$ administration). After an overnight fast, the study drugs were administered at approximately 8:00 a.m. The time of swallowing the liquid $\mathrm{MB}$ formulation and/or the $\mathrm{CQ}$ tablets and the end of the i.v. injection were defined as $0 \mathrm{~h}$ and $0 \mathrm{~min}$. All previous and following study times refer relatively to this time point. During the initial $10 \mathrm{~h}$ after the administration of the study drugs the participants were asked to stay in a semi-recumbent position, and they were only allowed to leave the Clinical Research Unit after the 10 h-blood sample had been drawn. Alcoholic and caffeinated beverages were not allowed from the time the study drug was administered until the last blood sample for the pharmacokinetics analysis had been drawn $(24 \mathrm{~h}$ in the bioavailability study and $72 \mathrm{~h}$ in the supplemental study). Caffeine-free beverages were supplied during all study days. For lunch and supper, standardized meals were provided by the hospital.

On study day 1 or 8 , respectively, $50 \mathrm{mg} \mathrm{MB}$, dissolved in $10 \mathrm{~mL} 0.9 \% \mathrm{NaCl}$, was injected i.v. over $9.5 \mathrm{~min}$, followed by a bolus of $10 \mathrm{~mL} 0.9 \% \mathrm{NaCl}$ within $30 \mathrm{~s}$. Alternatively, $20 \mathrm{~mL}$ of the liquid oral preparation containing $25 \mathrm{mg} \mathrm{MB} / \mathrm{mL}$, corresponding to $500 \mathrm{mg} \mathrm{MB}$ orally, was taken together with $180 \mathrm{~mL}$ water. On study day 15 , a single oral dose of $750 \mathrm{mg}$ CQ (three tablets, equivalent to an initial therapeutic dose in normal weight adults), either alone or together with $500 \mathrm{mg} \mathrm{MB}(20 \mathrm{~mL}$ of the liquid oral preparation), was taken together with $180 \mathrm{~mL}$ water. When MB had to be injected i.v., blood samples [7.5-mL blood samples into a heparinized tube (for plasma drug concentrations) and $2.7 \mathrm{~mL}$ into an EDTA tube (for whole blood drug concentrations] were drawn prior to medication (at the end of the injection $=0 \mathrm{~min}$ ) and at $5,10,15,25,35$, 45 and $60 \mathrm{~min}$ and $2,3,4,6,8,10,23.5$, and $24 \mathrm{~h}$ after drug administration. When MB was taken orally, equivalent samples were drawn prior to medication $(=0 \mathrm{~min})$, and at $30,60,90$, and $120 \mathrm{~min}$ and at 3, 4, 5, 6, 7, 8, 9, 10, 23.5, and $24 \mathrm{~h}$ after drug administration. On study day 15 , the timing of blood sampling was the same as after oral MB intake; however, the 48-h and 72-h samples were added 
because of the long half life of CQ. Heparinized blood samples were centrifuged immediately at $+4^{\circ} \mathrm{C}$; plasma and whole blood samples were kept frozen at $-20^{\circ} \mathrm{C}$ until analysis.

For safety reasons a 12-lead ECG was recorded continuously for the first $4 \mathrm{~h}$ following the administration of CQ. Blood pressure was measured simultaneously at constant intervals. Both were registered and documented using the Surveyor II Monitoring System (Mortara Instruments, Essen, Germany). Female participants had to ensure effective contraceptive measures (co-application of two independent measures recommended) during the entire period of study participation and for 6 months after the administration of CQ. Any adverse event had to be adequately documented. The outcome was followed until recovery or stabilization of the participant's state.

\section{Analytical methods}

Plasma and whole blood concentrations of MB were determined by selective and sensitive methods based on protein precipitation and cation exchange chromatography coupled to electrospray ionisation (ESI) tandem mass spectrometry (MS/MS); these method had been validated according to the Food and Drug Administration's (FDA) standards [3]. Acidic protein precipitation with acetonitrile and trifluoroacetic acid was used for whole blood and plasma. Sample extracts were chromatographed on a mixed mode column (cation exchange/reversed phase, Uptisphere MM1) using an aqueous ammonium acetate/acetonitrile gradient. Methylene blue was quantified with MS/MS in the selected reaction monitoring mode using ESI and methylene violet 3RAX as the internal standard. Depending on the sample volume (whole blood and plasma: $250 \mu \mathrm{L}$ ), the method was linear at least within the range of $75 \mathrm{ng} / \mathrm{mL}$ and $10,000 \mathrm{ng} / \mathrm{mL}$, respectively, and the limit of quantification (LOQ) in all matrices was $75 \mathrm{ng} / \mathrm{mL}$. Batch-to-batch accuracies of the whole blood and plasma methods varied between -4.5 and $+6.6 \%$ and -3.7 and $+7.5 \%$, respectively, with the corresponding precision ranging from 3.8 to $11.8 \% \mathrm{CV}$.

The concentrations of CQ in the plasma and whole blood were determined using high performance liquid chromatography (HPLC) with ultra-violet (UV) detection after liquid/ liquid extraction. These methods were based on published methods [20], but were modified in terms of chromatographic and sample extraction details as described in [26]. The LOQ in whole blood and plasma was $24 \mathrm{ng} / \mathrm{mL}$.

Pharmacokinetic calculations and biometrical evaluation

No published data were available allowing sample size calculation for determination of the absolute bioavailability of MB. The calculation of pharmacokinetic parameters and biometrical evaluation of $\mathrm{MB}$ and $\mathrm{CQ}$ data were carried out using WinNonlin ver. 5.2 software (Pharsight Corporation, Mountain View, CA). The area under the substrate concentration time curves (AUC) was calculated by the trapezoidal rule with linear interpolation. The absolute bioavailability of $\mathrm{MB}$ (total $\mathrm{AUC}_{\text {oral }} /$ total $\mathrm{AUC}_{\mathrm{iv}}$, corrected for the difference in dosage) was determined intra-individually. The maximum concentration $\mathrm{C}_{\max }$ and the time to reach this concentration $\mathrm{T}_{\max }$ were obtained directly from the raw data. The terminal elimination halflife was determined according to $T_{1 / 2}=\ln 2 / \lambda_{z}$. A maximum of seven data points was used to calculate $T_{1 / 2}$; in three participants, only three data points were used in study part A after oral MB administration. Mean values \pm standard deviation (SD) are given for all measured variables. A Wilcoxon matched-pairs signed-rank test was calculated for the intra-individual comparison of the total AUC $\left(\mathrm{AUC}_{0-\infty}\right)$ after oral $\mathrm{MB}$ alone and combined MB-CQ treatment, assessed separately for plasma and whole blood respectively. The $\mathrm{AUC}_{0-\infty}$ of $\mathrm{CQ}$ was compared between plasma and whole blood, separately for CQ alone and for the combined MB-CQ treatment. The level of significance for a difference between two variables was set at the $5 \%$ level one-sided, corresponding to a two-sided $90 \%$ confidence interval (CI).

\section{Results}

MB plasma concentrations

MB plasma concentration time curves are shown in Figs. 2 and 3 (note the different time and concentration scales). Concentrations rose promptly after oral application and were well above the detection limit after $24 \mathrm{~h}$ or even

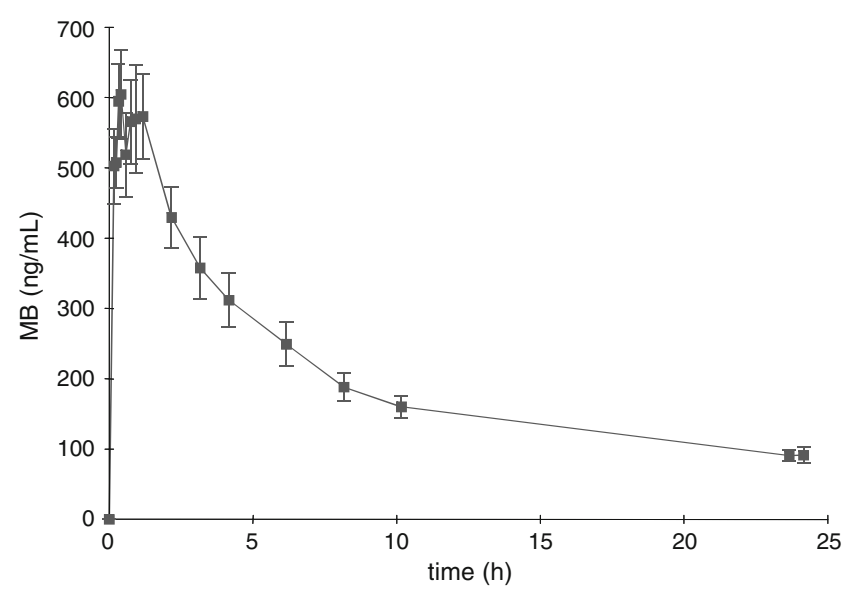

Fig. 2 Mean \pm standard error of the mean (SEM) for MB plasma concentrations after i.v. injection of $50 \mathrm{mg} \mathrm{MB}$ 


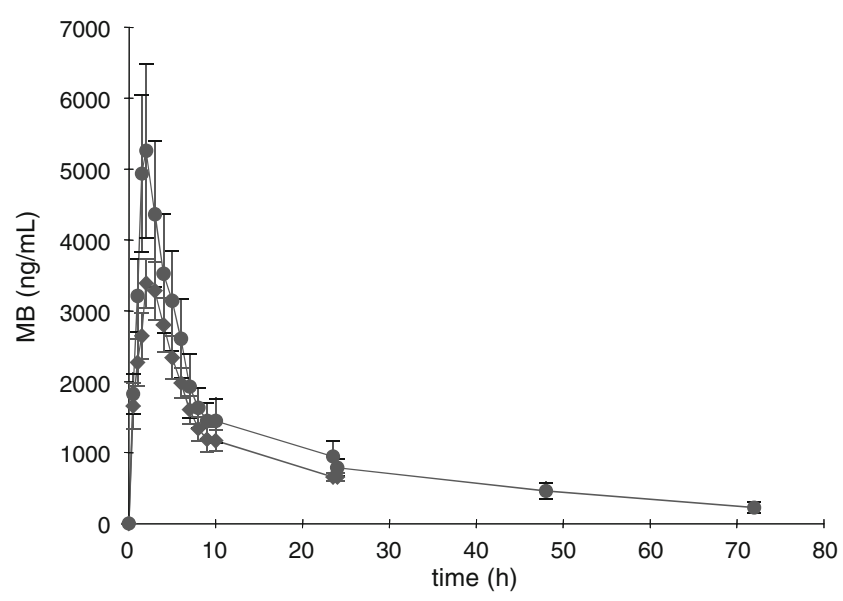

Fig. 3 Mean ( \pm SEM) for MB plasma concentrations after oral intake of $500 \mathrm{mg} \mathrm{MB}$ either alone (filled diamond) or combined with $750 \mathrm{mg}$ chloroquine (filled circles). Note the different plasma concentration and time scales in Figs. 2 and 3 as a consequence of the different dosing regimens

$72 \mathrm{~h}$. Individual pharmacokinetic characteristics are given in Table 1. The mean $( \pm \mathrm{SD})$ total area under the plasma concentration time curve $\left(\mathrm{AUC}_{0-\infty}\right)$ was $7,639 \pm$ $3,384 \mathrm{ng} / \mathrm{mL}^{*} \mathrm{~h}$ when given i.v. (Table 1) and 51,171 \pm $17,147 \mathrm{ng} / \mathrm{mL}^{*} \mathrm{~h}$ when given orally (part $\mathrm{A}$; dosage ratio i.v./ oral $=1: 10 ; n=15)$. Based on these data, the MB fraction absorbed (bioavailability) amounts to $72.3 \pm$ $23.9 \%$. Based on the AUC covered by MB measurements $\left(\mathrm{AUC}_{0-24}\right)$, the bioavailability amounted to $68.5 \pm 16.4 \%$. In participant No. 1, who had vomited within $30 \mathrm{~min}$ after dosing, $\mathrm{AUC}_{0-24}$ and $\mathrm{C}_{\max }$ were in the lower range, but not exceptionally low. $\mathrm{AUC}_{0-\infty}$ and the $\mathrm{MB}$ fraction absorbed (bioavailability) were above mean values. This suggests that vomiting did not have a major influence.

When $\mathrm{MB}$ was combined with $\mathrm{CQ}$ and both were given orally (part $\mathrm{B}, n=8$ ), the $\mathrm{AUC}_{0-\infty}$ of $\mathrm{MB}$ was $76,897 \pm$ $46,037 \mathrm{ng} / \mathrm{mL}^{*} \mathrm{~h}$. The mean plasma $\mathrm{MB} \mathrm{AUC}_{0-\infty}$ in participants who had received $\mathrm{MB}$ alone in part $\mathrm{A}$ and the combined MB-CQ treatment in part B was $45,449 \pm 22,039$ and $76,897 \pm 46,037 \mathrm{ng} / \mathrm{mL}^{*} \mathrm{~h}$, respectively $(n=8)$; an intra-individual comparison showed a significant difference $(p \leq 0.016)$. In participant No. 11 , who had vomited within 30 min after dosing, the $\mathrm{AUC}_{0-72}$ and $\mathrm{AUC}_{0-\infty}$ were in the lower range of the data. The residual $A U C$ not covered by $\mathrm{MB}$ measurements $\left(\mathrm{AUC}_{0-\infty}-\mathrm{AUC}_{0-24}\right.$, study part A, 24-h drug determination) corresponded to $31.3 \pm 16.5$ and $33.6 \pm 11.8 \%$ of the total AUC after i.v. and oral $\mathrm{MB}$, respectively, and to $11.7 \pm 8.7 \%$ after combined MB-CQ treatment $\left(\mathrm{AUC}_{0-\infty}-\mathrm{AUC}_{0-72}\right.$, study part $\mathrm{B}$, 72-h drug determination). The mean plasma elimination half-lives, $\mathrm{T}_{1 / 2}$, of $\mathrm{MB}$ were $18.5 \pm 11.8,18.3 \pm 7.2$, and $24.7 \pm 9.4 \mathrm{~h}$ after i.v., oral, and combined MB-CQ administration, respectively. In participants No. 1 and 11 , who had vomited in study part A or B, respectively, seven and five data points, respectively, were available for calculating $T_{1 / 2}$. Therefore, the results are assumed to be sufficiently reliable despite vomiting.

MB whole blood concentrations

Individual pharmacokinetic characteristics are given in Table 2. The mean $\mathrm{AUC}_{0-\infty}$ was $6,467 \pm 3,311 \mathrm{ng} / \mathrm{mL} * \mathrm{~h}$ when given i.v., and $50,578 \pm 30,125 \mathrm{ng} / \mathrm{mL}^{*} \mathrm{~h}$ when given orally (dosage ratio i.v./ oral $=1: 10$ ). From these data, the fraction absorbed (bioavailability) amounts to $84.0 \pm 16.7 \%$ $(n=10)$. Based on the AUC covered by MB measurements $\left(\mathrm{AUC}_{0-24}\right)$, the bioavailability amounted to $81.7 \pm 16.9$. When MB was combined with CQ, both given orally, $(n=$ 8), the $\mathrm{AUC}_{0-\infty}$ of MB was $45,075 \pm 21,989 \mathrm{ng} / \mathrm{mL} * \mathrm{~h}$. The mean whole blood $\mathrm{MB} \mathrm{AUC}_{0-\infty}$ in participants who had received $\mathrm{MB}$ alone in part $\mathrm{A}$ and the combined $\mathrm{MB}-\mathrm{CQ}$ treatment in part B was 50,387 $\pm 35,138$ and $45,075 \pm$ $21,989 \mathrm{ng} / \mathrm{mL}^{*} \mathrm{~h}$, respectively $(n=8)$; the difference is not significant. The mean $\mathrm{T}_{1 / 2}$ of $\mathrm{MB}$ were $13.6 \pm 3.7,14.7 \pm$ 4.4, and $19.4 \pm 5.6 \mathrm{~h}$ after i.v., oral, and combined MB-CQ administration, respectively. In participant No. 11, who had vomited within $30 \mathrm{~min}$ after dosing, the results were not remarkably different from the other data.

Ratio of whole blood to plasma MB concentrations (study part A)

In participants who had received MB i.v. and in whom a complete set of the corresponding whole blood and plasma $\mathrm{AUC}_{0-\infty}$ had been obtained $(n=10)$, the mean ratio was $0.98 \pm 0.39$. In participants who had received MB orally and in whom a complete set of the corresponding whole blood and plasma $\mathrm{AUC}_{0-\infty}$ had been obtained $(n=12)$, the mean ratio was $1.07 \pm 0.44$.

CQ plasma and whole blood concentrations (study part B)

Mean CQ plasma and whole blood concentrations are shown in Fig. $4(n=14)$, individual pharmacokinetic characteristics are given in Table 3. The mean CQ total area under the plasma concentration time curve $\left(\mathrm{AUC}_{0-\infty}\right)$ was $8,385 \pm 3,018 \mathrm{ng} / \mathrm{mL} * \mathrm{~h}$ when given alone $(n=6)$, and $8,80 \pm 4126 \mathrm{ng} / \mathrm{mL}^{*} \mathrm{~h}$ when given with MB $(n=8)$. The mean CQ whole blood $\mathrm{AUC}_{0-\infty}$ was $35,029 \pm 12,448$ $\mathrm{ng} / \mathrm{mL}^{*} \mathrm{~h}$ when CQ was given alone $(n=6)$, and $34,999 \pm$ $16,794 \mathrm{ng} / \mathrm{mL} * \mathrm{~h}$ when given with $\mathrm{MB}(n=8)$.

An intra-individual comparison of CQ whole blood and plasma $\mathrm{AUC}_{0-\infty}$ after CQ intake alone $(n=6$; mean values see above) showed a significant difference $(p<0.05)$; a comparison of $\mathrm{CQ}$ whole blood and plasma $\mathrm{AUC}_{0-\infty}$ after 
Table 1 Individual pharmacokinetic characteristics and mean values \pm $\mathrm{SD}$ of methylene blue (MB) in plasma after a single intravenous dose $(50 \mathrm{mg})$ and a single oral dose $(500 \mathrm{mg})$ of $\mathrm{MB}$, and after the combination of a single oral dose of $\mathrm{MB}(500 \mathrm{mg})$ and a single oral dose of chloroquine $(750 \mathrm{mg}$ )

\begin{tabular}{|c|c|c|c|c|c|c|c|}
\hline $\begin{array}{l}\text { Mode of } \\
\text { administration/subject (nr.) }\end{array}$ & Part of study & $\mathrm{AUC}_{0-\infty}\left(\mathrm{ng} / \mathrm{mL}^{*} \mathrm{~h}\right)$ & $\mathrm{AUC}_{0-24}\left(\mathrm{ng} / \mathrm{mL}^{*} \mathrm{~h}\right)$ & $\mathrm{C}_{\max }(\mathrm{ng} / \mathrm{mL})$ & $\mathrm{T}_{\max }(\mathrm{h})$ & $\mathrm{T}_{1 / 2}(\mathrm{~h})$ & $\mathrm{F}_{0-\infty}(\%)$ \\
\hline \multicolumn{8}{|l|}{ Intravenous } \\
\hline 1 & A & $7,279.4$ & $3,619.5$ & 655.2 & 0.33 & 28.5 & \\
\hline 2 & A & $5,611.5$ & $4,316.1$ & 682.0 & 0.42 & 12.0 & \\
\hline 3 & $\mathrm{~A}$ & $7,426.0$ & $6,088.6$ & 688.8 & 0.42 & 10.3 & \\
\hline 4 & A & $7,762.7$ & $6,254.1$ & 919.0 & 0.75 & 10.7 & \\
\hline 5 & A & $12,494.6$ & $6,969.7$ & $1,071.2$ & 0.92 & 17.3 & \\
\hline 6 & A & $4,936.2$ & $3,565.0$ & 909.2 & 0.17 & 18.4 & \\
\hline 7 & A & $15,803.8$ & $5,875.6$ & 692.8 & 0.33 & 48.3 & \\
\hline 8 & A & $6,608.0$ & $4,347.3$ & 637.9 & 0.42 & 18.1 & \\
\hline 10 & A & $10,926.3$ & $3,972.1$ & 389.9 & 1.17 & 40.9 & \\
\hline 11 & A & $3,332.3$ & $2,609.0$ & 411.1 & 0.33 & 12.2 & \\
\hline 12 & A & $6,248.1$ & $4,863.5$ & 654.3 & 0.17 & 14.6 & \\
\hline 13 & $\mathrm{~A}$ & $10,072.8$ & $9,103.2$ & $1,384.8$ & 0.92 & 7.7 & \\
\hline 14 & A & $7,109.2$ & $5,750.8$ & 932.0 & 0.17 & 11.6 & \\
\hline 15 & A & $4,712.0$ & $3,354.8$ & 705.5 & 0.33 & 15.4 & \\
\hline 16 & A & $4,268.0$ & $3,236.1$ & 491.8 & 0.75 & 11.6 & \\
\hline Mean & & 7,639 & 4,928 & 748 & 0.5 & 18.5 & \\
\hline SD & & 3,384 & 1,736 & 260 & 0.3 & 11.8 & \\
\hline CV (\%) & & 44.3 & 35.2 & 34.8 & 62.6 & 63.7 & \\
\hline \multicolumn{8}{|l|}{ Oral } \\
\hline $1^{\mathrm{a}}$ & A & $65,041.6$ & $24,042.6$ & $3,206.1$ & 2.0 & 38.0 & 89.4 \\
\hline 2 & $\mathrm{~A}$ & $58,435.6$ & $32,866.5$ & $3,342.6$ & 2.0 & 24.4 & 104.2 \\
\hline 3 & A & $55,285.7$ & $36,875.4$ & $4,299.9$ & 3.0 & 17.0 & 74.5 \\
\hline 4 & A & $64,885.4$ & $49,019.2$ & $4,668.3$ & 3.0 & 14.0 & 83.6 \\
\hline 5 & A & $50,598.4$ & $35,063.2$ & $5,298.5$ & 2.0 & 16.5 & 40.5 \\
\hline 6 & A & $37,249.5$ & $24,242.1$ & $2,668.6$ & 2.0 & 22.5 & 75.5 \\
\hline 7 & A & $49,658.8$ & $34,522.0$ & $3,833.1$ & 2.0 & 15.9 & 31.4 \\
\hline 8 & A & $62,018.2$ & $45,249.5$ & $5,540.1$ & 2.0 & 13.8 & 93.9 \\
\hline 10 & A & $57,616.6$ & $35,555.6$ & $4,395.8$ & 2.0 & 19.8 & 52.7 \\
\hline 11 & A & $33,740.9$ & $18,871.8$ & $1,833.1$ & 2.0 & 24.5 & 101.3 \\
\hline 12 & $\mathrm{~A}$ & $53,237.7$ & $29,985.9$ & $3,216.8$ & 2.0 & 22.0 & 85.2 \\
\hline 13 & A & $80,917.7$ & $64,624.9$ & $6,909.8$ & 3.0 & 10.7 & 80.3 \\
\hline 14 & A & $60,176.1$ & $46,602.6$ & $5,964.8$ & 1.0 & 12.1 & 84.7 \\
\hline 15 & A & $16,965.9$ & $14,209.4$ & $1,876.3$ & 2.0 & 9.8 & 36.0 \\
\hline 16 & A & $21,738.6$ & $14,927.5$ & $1,515.6$ & 3.0 & 13.8 & 50.9 \\
\hline Mean & & 51,171 & 33,777 & 3,905 & 2.2 & 18.3 & 72.3 \\
\hline SD & & 17,147 & 13,774 & 1,599 & 0.6 & 7.2 & 23.9 \\
\hline CV (\%) & & 33.5 & 40.8 & 41.0 & 25.5 & 39.6 & 33.0 \\
\hline Oral MB-CQ combination & & & $\mathrm{AUC}_{0-24}$ & & & & \\
\hline 2 & $\mathrm{~B}$ & $54,242.9$ & $50,454.5$ & $4,112.0$ & 2.0 & 22.8 & \\
\hline 4 & $\mathrm{~B}$ & $75,912.1$ & $63,066.6$ & $6,195.7$ & 2.0 & 23.3 & \\
\hline 6 & $\mathrm{~B}$ & $47,732.2$ & $45,709.4$ & $4,163.4$ & 1.5 & 18.7 & \\
\hline 7 & $\mathrm{~B}$ & $105,995.5$ & $86,315.6$ & $6,425.0$ & 2.0 & 35.4 & \\
\hline $11^{\mathrm{a}}$ & $\mathrm{B}$ & $57,282.7$ & $41,556.9$ & $2,141.5$ & 1.0 & 41.2 & \\
\hline 13 & $\mathrm{~B}$ & $179,251.5$ & $157,313.9$ & $12,915.7$ & 2.0 & 26.1 & \\
\hline 15 & $\mathrm{~B}$ & $50,632.0$ & $48,456.1$ & $4,331.2$ & 2.0 & 16.1 & \\
\hline 16 & $\mathrm{~B}$ & $44,130.4$ & $42,850.4$ & $3,096.8$ & 6.0 & 13.7 & \\
\hline Mean & & 76,897 & 66,965 & 5,423 & 2.3 & 24.7 & \\
\hline SD & & 46,037 & 39,364 & 3,347 & 1.5 & 9.4 & \\
\hline CV (\%) & & 59.9 & 58.8 & 61.7 & 66.3 & 38.3 & \\
\hline
\end{tabular}

$\mathrm{SD}$, Standard deviation; CV, coefficient of variation; $\mathrm{AUC}$, area under the substrate concentration time curve; $\mathrm{C}_{\max }$, maximum concentration; $\mathrm{T}_{\max }$, time to reach maximum concentration; $\mathrm{T}_{1 / 2}$, terminal elimination half-life

${ }^{\text {a }}$ Subject vomited within the initial 30 min after drug administration. 
Table 2 Individual pharmacokinetic characteristics and mean values $\pm \mathrm{SD}$ of $\mathrm{MB}$ in whole blood after a single intravenous dose (50 mg) and a single oral dose $(500 \mathrm{mg})$ of $\mathrm{MB}$, and after the combination of a single oral dose of $\mathrm{MB}(500 \mathrm{mg})$ and a single oral dose of CQ (750 mg)

\begin{tabular}{|c|c|c|c|c|c|c|c|}
\hline Mode of administration/subject (nr.) & Part & $\mathrm{AUC}_{0-\infty}\left(\mathrm{ng} / \mathrm{mL}^{*} \mathrm{~h}\right)$ & $\mathrm{AUC}_{0-24}(\mathrm{ng} / \mathrm{mL} * \mathrm{~h}$ & $\mathrm{C}_{\max }(\mathrm{ng} / \mathrm{mL})$ & $\mathrm{T}_{\max }(\mathrm{h})$ & $\mathrm{T}_{1 / 2}(\mathrm{~h})$ & $\mathrm{F}_{0-\infty}(\%)$ \\
\hline \multicolumn{8}{|l|}{ Intravenous } \\
\hline 3 & A & $8,404.4$ & $7,200.8$ & $1,084.8$ & 0.58 & 8.6 & \\
\hline 4 & A & $12,848.4$ & $11,282.3$ & $2,063.2$ & 0.17 & 9.2 & \\
\hline 5 & A & $8,653.1$ & $4,968.6$ & $1,386.7$ & 0.17 & 20.5 & \\
\hline 6 & A & $7,500.4$ & $5,835.0$ & $1,624.5$ & 0.17 & 12.5 & \\
\hline 11 & A & $3,701.3$ & $2,534.5$ & $1,695.7$ & 0.17 & 16.0 & \\
\hline 12 & A & $4,810.4$ & $3,457.3$ & $1,241.3$ & 0.17 & 13.0 & \\
\hline 13 & A & $8,944.1$ & $6,214.3$ & $1,506.4$ & 0.33 & 16.0 & \\
\hline 14 & A & $2,407.0$ & $1,581.9$ & 503.2 & 0.17 & 15.9 & \\
\hline 15 & A & $3,796.1$ & $2,912.4$ & $2,599.7$ & 0.17 & 14.0 & \\
\hline 16 & A & $3,604.6$ & $2,948.5$ & 478.8 & 0.17 & 10.5 & \\
\hline Mean & & 6,467 & 4,894 & 1,418 & 0.22 & 13.6 & \\
\hline $\mathrm{SD}$ & & 3,311 & 2,888 & 650 & 0.14 & 3.7 & \\
\hline CV (\%) & & 51.2 & 59.0 & 45.8 & 59.8 & 26.9 & \\
\hline \multicolumn{8}{|l|}{ Oral } \\
\hline 2 & A & $33,977.4$ & $24,299.7$ & $2,189.8$ & 3.0 & 13.1 & n.d. \\
\hline 3 & A & $76,626.4$ & $54,998.7$ & $4,951.6$ & 4.0 & 15.5 & 91.2 \\
\hline 4 & A & $124,521.4$ & $84,253.6$ & $7,920.8$ & 2.0 & 15.4 & 96.9 \\
\hline 5 & A & $54,920.9$ & $31,897.4$ & $3,372.4$ & 2.0 & 18.2 & 63.5 \\
\hline 6 & A & $50,276.9$ & $37,794.3$ & $4,177.5$ & 1.5 & 14.9 & 67.0 \\
\hline 7 & A & $29,940.8$ & $21,777.7$ & $2,757.0$ & 1.5 & 13.9 & n.d.* \\
\hline 11 & A & $29,902.0$ & $24,461.3$ & $2,708.0$ & 2.0 & 9.7 & 80.8 \\
\hline 12 & A & $46,756.6$ & $26,429.0$ & $3,586.2$ & 1.0 & 25.9 & 97.2 \\
\hline 13 & A & $80,177.0$ & $63,012.9$ & 7,798.6 & 2.0 & 12.9 & 89.6 \\
\hline 14 & A & $25,531.2$ & $17,808.6$ & $2,448.4$ & 1.0 & 16.6 & 106.1 \\
\hline 15 & A & $21,118.0$ & $18,877.7$ & $2,607.8$ & 3.0 & 8.7 & 55.6 \\
\hline 16 & A & $33,184.2$ & $25,215.2$ & $2,971.4$ & 3.0 & 12.2 & 92.1 \\
\hline Mean & & 50,578 & 35,902 & 3,957 & 2.2 & 14.7 & 84.0 \\
\hline SD & & 30,125 & 20,766 & 1,981 & 0.9 & 4.4 & 16.7 \\
\hline CV (\%) & & 59.6 & 57.8 & 50.1 & 42.1 & 30.0 & 19.9 \\
\hline Oral MB-CQ combination & & & $\mathrm{AUC}_{0-72}$ & & & & \\
\hline 2 & $\mathrm{~B}$ & $33,329.9$ & $30,904.4$ & $2,477.9$ & 1.5 & 22.6 & \\
\hline 4 & $\mathrm{~B}$ & $68,683.4$ & $56,449.1$ & $4,011.3$ & 2.0 & 19.1 & \\
\hline 6 & $\mathrm{~B}$ & $31,068.8$ & $30,470.5$ & $2,862.1$ & 2.0 & 14.5 & \\
\hline 7 & $\mathrm{~B}$ & $41,616.6$ & $36,963.5$ & $2,388.1$ & 1.5 & 26.0 & \\
\hline $11^{\mathrm{a}}$ & $\mathrm{B}$ & $35,930.1$ & $32,175.2$ & $4,865.0$ & 1.5 & 24.5 & \\
\hline 13 & $\mathrm{~B}$ & $89,357.7$ & $79,738.4$ & $5,765.3$ & 3.0 & 23.1 & \\
\hline 15 & $\mathrm{~B}$ & $30,651.7$ & $29,532.6$ & $2,650.3$ & 3.0 & 10.4 & \\
\hline 16 & B & $29,960.2$ & $28,961.8$ & $2,180.2$ & 4.0 & 15.0 & \\
\hline Mean & & 45,075 & 40,649 & 3,400 & 2.3 & 19.4 & \\
\hline SD & & 21,989 & 18,212 & 1,327 & 0.9 & 5.6 & \\
\hline CV (\%) & & 48.8 & 44.8 & 39.0 & 39.9 & 28.8 & \\
\hline
\end{tabular}

n.d., Not determined

${ }^{a}$ Subject vomited within the initial 30 min after drug administration.

combined MB-CQ intake ( $n=8$; mean values see above) gave a highly significant difference $(p \leq 0.001)$. There was no influence of $\mathrm{MB}$ on the pharmacokinetics of CQ. Therefore, the mean ratio of CQ whole blood to plasma concentrations was assessed for the total group $(n=14)$; the ratio remained close to 4 during the entire period of observation.
Safety and tolerability of the study medication

No relevant safety concerns arose during the study; no serious adverse event occurred. However, the tolerability of MB was limited, mainly due to an intensively bitter and metallic taste of the liquid oral formulation which resulted in immediate nausea after 14 of 23 drug administrations and provoked 


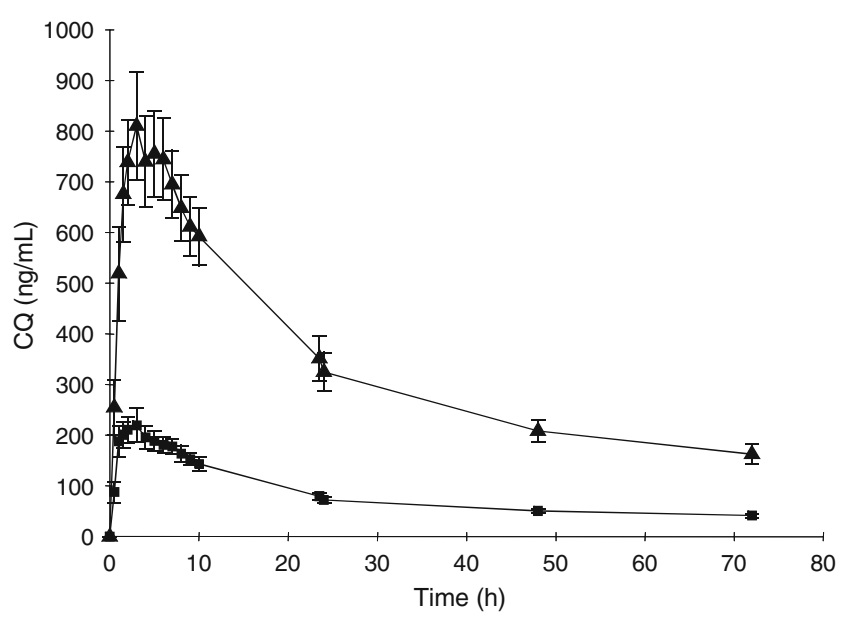

Fig. 4 Mean ( \pm SEM) chloroquine $(C Q)$ whole blood (filled triangles) and plasma concentrations (filled squares)

vomiting in three occasions - once $7 \mathrm{~min}$ after MB alone and twice after the combination of MB and CQ (after 25 min and about $1 \mathrm{~h}$ respectively). One male participant vomited $20 \mathrm{~min}$ after i.v. administration of MB, but not after oral intake. Mild diarrhea was reported five times after MB administration, and mild and self-limiting dysuria was reported twice after MB. On three occasions, a mild to moderate headache was reported, twice in association with CQ intake and once after i.v. MB. Completely reversible blue staining of the oral mucosa and teeth (including foreign material) for several hours and of the urine for several days was noticed by all participants, but this was no problem.

\section{Discussion}

The development of MB for the treatment of malaria was initially primarily intended for countries where other treatments are too expensive to be sufficiently available for the large populations affected by this disease [17-19, 31]. The MB-based treatment of uncomplicated malaria in SubSaharan Africa was first investigated in combination with CQ [17-19]. When MB was given at a dose of $2 \mathrm{mg} / \mathrm{kg}$ twice daily over 3 days, treatment was safe, even in G6PDdeficient adults and children [17, 18], but it was not sufficiently effective [18]. In a subsequent dose-finding study in a comparable population of young children, a significantly better efficacy was demonstrated when threeto sixfold higher MB doses were given over 3 days. Such MB doses again were safe, even in G6PD deficient children. However, despite a significant reduction, especially in early treatment failure rates, an unacceptably high rate of recrudescence, most likely due to the high background resistance of the local parasites against CQ, was observed [19]. This has led to the search for other MB combinations [31]. However, given the most recent problem - that of parasite resistance against artemisinin derivatives [22] - MB may even gain importance in populations who do have sufficient access to other effective therapies. A reevaluation of $\mathrm{MB}$ as an antimalarial agent is indeed reasonable based on earlier reports of its beneficial therapeutic effects $[7,10,14]$ and more recent knowledge on its mechanisms of action [27]. However, the therapeutic efficacy of oral treatment regimens is not only related to the properties of the active drug, but also to its bioavailability. Very little information on systemic MB concentrations in humans was available at the onset of this investigation, and what was available suggested a very low bioavailability. Our own data on the interaction of MB and CQ from a previous study [26] did not allow us to estimate bioavailability. In a study comparing $100 \mathrm{mg}$ MB orally and i.v., the $\mathrm{AUC}_{0-4 \mathrm{~h}}$ of whole blood $\mathrm{MB}$ concentrations was only about $1 \%$ of the corresponding value after i.v. injection [24]. Therefore, in the investigation reported here, the oral dose was relatively high, whereas the i.v. dose was less than that in the earlier bioavailability study [24] and less than used for some diagnostic procedures [15]. However, in contrast to our expectation, bioavailability turned out to be high: about two thirds of the oral dose of MB taken as an aqueous solution reached the systemic circulation. One important explanation for this finding is probably the fact that the sensitivity of analytical procedures has improved remarkably in the time between our study and previous ones [3]; this has enabled us to detect total MB concentrations in plasma and whole blood much better than previously, with a difference in the order of 100:1. In our interaction study with CQ [26], we probably quantified only the unbound fraction, and it is possible that other published reports also relate to free rather than to total $\mathrm{MB}$ plasma and whole blood concentrations.

Our intention was to clarify the order of magnitude of MB bioavailability. This information is essential to the decision-making process on whether or not the development of MB as an antimalarial drug should be pursued. We found that the bioavailability of $\mathrm{MB}$ is certainly high enough to justify continuation. The fact that there was appreciable inter-individual variation and that the extrapolated AUC in study part A on average exceeded the usual upper limit of $20 \%$ is not a relevant issue because the bioavailability values based on the total AUC and on the $\mathrm{AUC}_{0-24}$ are similar. From the data generated in study part $\mathrm{B}$, with an observation period of $72 \mathrm{~h}$, which resulted in a low residual AUC of only about $12 \%$, we can conclude that investigations of a new taste-masked pharmaceutical formulation of MB should be based on 72-h or 96-h observation periods to also meet the strict criteria set for bioavailability studies requested by regulatory agencies for pre-marketing authorization. In participants No. 1 and No. 
Table 3 Individual pharmacokinetic characteristics and mean values $\pm \mathrm{SD}$ of CQ in plasma and whole blood after a single oral dose of CQ $(750 \mathrm{mg})$, and after the combination of a single oral dose of MB $(500 \mathrm{mg})$ and a single oral dose of CQ (750 mg)

\begin{tabular}{|c|c|c|c|}
\hline $\begin{array}{l}\text { Drug therapy/subject } \\
\text { (nr.) }\end{array}$ & $\begin{array}{l}\mathrm{AUC}_{0-\infty} \\
\left(\mathrm{ng} / \mathrm{mL}^{*} \mathrm{~h}\right)\end{array}$ & $\begin{array}{l}\mathrm{C}_{\max } \\
(\mathrm{ng} / \mathrm{mL})\end{array}$ & $\begin{array}{l}\mathrm{T}_{\max } \\
\text { (h) }\end{array}$ \\
\hline & CQ plasma & & \\
\hline \multicolumn{4}{|l|}{ CQ alone/subject (nr.) } \\
\hline 1 & $10,161.1$ & 256.2 & 2.0 \\
\hline 3 & $4,330.2$ & 186.3 & 2.0 \\
\hline 5 & $12,928.6$ & 334.3 & 3.0 \\
\hline 8 & $6,905.8$ & 180.5 & 7.0 \\
\hline 12 & $9,180.0$ & 285.8 & 3.0 \\
\hline 14 & $6,805.3$ & 150.3 & 5.0 \\
\hline Mean & 8,385 & 232 & 3.7 \\
\hline $\mathrm{SD}$ & 3,018 & 71 & 2.0 \\
\hline CV (\%) & 36.0 & 30.7 & 53.6 \\
\hline \multicolumn{4}{|l|}{ CQ-MB combination } \\
\hline 2 & $13,224.5$ & 353.8 & 3.0 \\
\hline 4 & $5,498.7$ & 343.3 & 1.5 \\
\hline 6 & $13,750.5$ & 534.8 & 3.0 \\
\hline 7 & $7,932.0$ & 390.9 & 1.0 \\
\hline 11 & $1,784.8$ & 79.2 & 5.0 \\
\hline 13 & $9,287.9$ & 307.1 & 1.0 \\
\hline 15 & $9,262.3$ & 216.0 & 4.0 \\
\hline 16 & $4,696.8$ & 117.5 & 6.0 \\
\hline Mean & 8,180 & 293 & 3.1 \\
\hline $\mathrm{SD}$ & 4,126 & 150 & 1.9 \\
\hline \multirow[t]{2}{*}{ CV (\%) } & 50.4 & 51.1 & 60.7 \\
\hline & CQ whole blood & & \\
\hline \multicolumn{4}{|l|}{ CQ alone } \\
\hline 1 & $28,285.6$ & 630.0 & 1.5 \\
\hline 3 & $17,660.4$ & 631.6 & 2.0 \\
\hline 5 & $54,300.3$ & $1,214.5$ & 3.0 \\
\hline 8 & $38,794.6$ & 699.2 & 7.0 \\
\hline 12 & $40,122.7$ & 978.9 & 3.0 \\
\hline 14 & $31,012.7$ & 610.9 & 5.0 \\
\hline Mean & 35,029 & 794 & 3.6 \\
\hline SD & 12,448 & 248 & 2.1 \\
\hline CV (\%) & 35.5 & 31.2 & 57.5 \\
\hline \multicolumn{4}{|l|}{ CQ-MB combination } \\
\hline 2 & $47,927.0$ & $1,324.9$ & 3.0 \\
\hline 4 & $19,631.4$ & $1,013.7$ & 1.5 \\
\hline 6 & $64,346.1$ & $1,634.9$ & 3.0 \\
\hline 7 & $38,085.0$ & $1,111.4$ & 1.0 \\
\hline 11 & $17,046.2$ & 311.8 & 7.0 \\
\hline 13 & $44,774.3$ & $1,211.0$ & 2.0 \\
\hline 15 & $28,797.1$ & 689.8 & 2.0 \\
\hline 16 & $19,383.3$ & 483.3 & 2.0 \\
\hline Mean & 34,999 & 973 & 2.7 \\
\hline $\mathrm{SD}$ & 16,794 & 447 & 1.9 \\
\hline CV (\%) & 48.0 & 45.9 & 69.6 \\
\hline
\end{tabular}

11, who vomited within $30 \mathrm{~min}$ after dosing in study part A or $\mathrm{B}$, respectively, the results did not differ remarkably from the data of the other study participants; we therefore assume that the data on these two participants are sufficiently reliable.
Plasma and whole blood MB concentrations did not differ when only $\mathrm{MB}$ was administered alone, indicating that $\mathrm{MB}$ does not accumulate within a cellular compartment, such as the erythrocytes. Interestingly, MB plasma concentrations rose significantly when $\mathrm{MB}$ was given concurrently with $\mathrm{CQ}$ in part B of our study, whereas whole blood concentrations remained unaffected. This study part was conducted because our former data had suggested a decrease in CQ whole blood concentrations during the combined treatment. The present data do not confirm this type of interaction as CQ kinetics were not influenced at all. Rather, a different interaction became apparent: higher concentrations of MB in plasma while whole blood concentrations are unchanged suggest a shift of MB from an intracellular compartment into the plasma. Further studies are needed to clarify this aspect, which could be relevant for the choice of future partner drugs in MB-based combination therapy.

The administration of oral MB was safe in this study, but the tolerability of oral MB was insufficient due to its bad taste. Developing $\mathrm{MB}$ as an antimalarial drug therefore has to include a further improvement of the pharmaceutical formulation. Since mainly liquid medicines are acceptable to very young children (only dispersible, very small granules to be mixed with food might be an alternative [8]), optimal taste masking is essential. A new type of formulation based on other principles than merely an aqueous solution [13] is a promising new approach for this goal. A taste-masked pediatric MB formulation was consequently developed and field-tested in the year 2007 (unpublished data). Other adverse events were mainly limited to temporary blue staining of the oral mucosa and teeth, including inserted dental material, mild and selflimiting dysuria, and blue discoloration of the urine. In contrast to a published report on permanent discoloration of a silicone intraocular lens by MB [29], all discolorations had been reversed within a few days among our participants.

The concentrations of CQ were also determined in our study. The whole blood maximum concentrations and the ratio of whole blood to plasma concentrations correspond to our previous observations, whereas the AUC values are not comparable due to the different dosage regimens. In this latest study, the participants received a single dose of CQ, whereas in our previous investigation [26] repetitive doses with a loading regimen were used. The present data are not sufficiently comparable with published data [6, 11, 12], mainly because we measured the drug levels only up to 72 hours after dosing.

\section{Conclusion}

The absolute bioavailability of MB given as an aqueous oral formulation is high. Therefore, bioavailability should not be considered to be a problem for the development of 
$\mathrm{MB}$ as an antimalarial drug. Plasma and whole blood MB concentrations do not differ, suggesting that MB is taken up into cellular blood components, but it does not accumulate intracellularly. The finding that the co-administration of MB and CQ increases MB plasma concentrations while whole blood concentrations are unchanged has potential consequences for the selection of partner drugs in MB-based combination therapies and deserves further investigation.

Acknowledgements The study was funded by an award from DSM Fine Chemicals Austria, Linz, Austria and by the Deutsche Forschungsgemeinschaft (SFB 544 "Control of Tropical Infectious Diseases" at the Ruprecht-Karls-University Heidelberg). We thank Mrs. Monika Maurer and Mrs. Brigitte Tayrouz for their excellent technical assistance.

Financial disclosure None of the authors has financial or other relationships that are relevant to the study.

\section{References}

1. Aeschlimann C, Kuepfer A, Schefer H, Cerny T (1998) Comparative pharmacokinetics of oral and intravenous ifosfamide/mesna/ methylene blue therapy. Drug Metab Dispos 26:883-890

2. Akoachere M, Buchholz K, Fischer E, Burhenne J, Haefeli WE, Schirmer RH, Becker K (2005) In vitro assessment of methylene blue on chloroquine-sensitive and -resistant Plasmodium falciparum strains reveals synergistic action with artemisinins. Antimicrob Agents Chemother 49:4592-4597

3. Burhenne J, Riedel K-D, Rengelshausen J, Meissner P, Mueller O, Mikus G, Haefeli WE, Walter-Sack I (2008) Quantification of cationic anti-malaria agent methylene blue in different human biological matrices using cation exchange chromatography coupled to tandem mass spectrometry. J Chromatogr B 863:273-282

4. DiSanto AR, Wagner JG (1972) Pharmacokinetics of highly ionized drugs II: methylene blue-absorption, metabolism, and excretion in man and dog after oral administration. J Pharm Sci 61:1086-1090

5. Donati A, Conti G, Loggi S, Muench C, Coltrinari R, Pelaia P, Pietropaoli P, Preiser J-C (2002) Does methylene blue administration to septic shock patients affect vascular permeability and blood volume. Crit Care Med 30:2271-2277

6. Ducharme J, Farinotti R (1996) Clinical pharmacokinetics and metabolism of chloroquine. Focus on recent advancements. Clin Pharmacokinet 31:257-274

7. Ehrlich P (1913) Chemotherapeutics: scientific principles, methods, and results. Lancet 182:445-451

8. European Medicines Agency (EMEA) Committee for Medicinal Products for Human Use (2006) Reflection paper: Formulations of choice for the pediatric population. Available at: http://www. emea.europa.eu/pdfs/human/paediatrics/19481005en.pdf. Accessed 8 July 2008

9. Evora PR, Simon MR (2007) Role of nitric oxide production in anaphylaxis and its relevance for the treatment of anaphylactic hypotension with methylene blue. Ann Allergy Asthma Immunology 99:306-313

10. Ferreira C (1893) Sur l’emploi du bleu de méthylène dans la malaria infantile. Rev Ther Med Chir 488-525

11. Frisk-Holmberg M, Bergqvist Y, Termond E, Domeij-Nyberg B (1984) The single dose kinetics of chloroquine and its major metabolite desethylchloroquine in healthy subjects. Eur J Clin Pharmacol 26:521-530

12. Gustafsson LL, Walker O, Alván G, Beermann B, Estevez F, Gleisner L, Lindstroem B, Sjoeqvist F (1983) Disposition of chloroquine in man after single intravenous and oral doses. Br J Clin Pharmacol 15:471-479

13. Gut F, Schiek W, Haefeli WE, Walter-Sack I, Burhenne J (2008) Cation exchange resins as pharmaceutical carriers for methylene blue: Binding and release. Eur J Pharm Biopharm 69:582-587

14. Guttmann P, Ehrlich P (1891) Ueber die Wirkung des Methylenblau bei Malaria. Berlin Klin Wochenschr 28:953-956

15. Khan MA, North AP, Chadwick DR (2007) Prolonged postoperative altered mental status after methylene blue infusion during parathyroidectomy: a case report and review of the literature. Ann R Coll Surg Eng 89:W9-W11

16. Kuepfer A, Aeschlimann C, Wermuth B, Cerny T (1994) Prophylaxis and reversal of ifosfamide encephalopathy with methylene blue. Lancet 343:763-764

17. Mandi G, Witte S, Meissner P, Coulibaly B, Mansmann U, Rengelshausen J, Schiek W, Jahn A, Sanon M, Wuest K, Walter-Sack I, Mikus G, Burhenne J, Riedel K-D, Schirmer H, Kouyaté B, Mueller O (2005) Safety of the combination of chloroquine and methylene blue in healthy adult men with G6PD deficiency from rural Burkina Faso. Trop Med Int Health $10: 32-38$

18. Meissner P, Mandi G, Witte S, Coulibaly B, Mansmann U, Rengelshausen J, Schiek W, Jahn A, Sanon M, Tapsoba T, Walter-Sack I, Mikus G, Burhenne J, Riedel K-D, Schirmer H, Kouyaté B, Mueller O (2005) Safety of the combination of chloroquine and methylene blue in the treatment of uncomplicated falciparum malaria in young children of Burkina Faso. Malaria J 4:45

19. Meissner PE, Mandi G, Coulibaly B, Witte S, Tapsoba T, Mansmann U, Rengelshausen J, Schiek W, Jahn A, Walter-Sack I, Mikus G, Burhenne J, Riedel K-D, Schirmer RH, Kouyate B, Mueller O (2006) Methylene blue for malaria in Africa: results from a dose-finding study in combination with chloroquine. Malaria $\mathrm{J}$ $5: 84$

20. Minzi OM, Rais M, Svensson JO, Gustafsson LL, Ericsson O (2003) High-performance chromatographic method for determination of amodiaquine, chloroquine and their monodesethyl metabolites in biological samples. J Chromatogr B Analyt Technol Biomed Life Sci 783:473-480

21. Neto AMO, Duarte NM, Vicente WVA, Viaro F, Evora PRB (2003) Methylene blue: an effective treatment for contrast medium-induced anaphylaxis. Med Sci Monit 9:CS102-CS106

22. Noedl H, Chanthap L, Se Y, Socheat D, Peou S, Schaechter K, Srivichai S, Teja-Isavadharm P, Smith B, Jongsakul K, Surasri S, Fukuda M (2007) Artemisinin resistance in Cambodia. Oral presentation, 5th Eur Congress Trop Med Int Health. Amsterdam

23. Pelgrims J, De Vos F, Van den Brande J, Schrijvers D, Prové A, Vermorken JB (2000) Methylene blue in the treatment and prevention of ifosfamide-induced encephalopathy: report of 12 cases and review of the literature. Br J Cancer 82:291-294

24. Peter C, Hongwan D, Kuepfer A, Lauterburg BH (2000) Pharmacokinetics and organ distribution of intravenous and oral methylene blue. Eur J Clin Pharmacol 56:247-250

25. Politis C, Kavallierou L, Hantziara S, Katsea P, Triantaphylou V, Richardson C, Tsoutsos D, Anagnostopoulos N, Gorgolidis G, Ziroyannis P (2007) Quality and safety of fresh-frozen plasma inactivated and leuco-reduced with the Theraflex methylene blue system including the Blueflex filter: 5 years' experience. Vox Sang 92:319-326

26. Rengelshausen J, Burhenne J, Froehlich M, Tayrouz Y, Singh SK, Riedel K-D, Mueller O, Hoppe-Tichy T, Haefeli WE, Mikus G, 
Walter-Sack I (2004) Pharmacokinetic interaction of chloroquine and methylene blue combination against malaria. Eur J Clin Pharmacol 60:709-715

27. Schirmer RH, Coulibaly B, Stich A, Scheiwein M, Merkle H, Eubel J, Becker K, Becher H, Mueller O, Zich T, Schiek W, Kouyaté B (2003) Methylene blue as an antimalarial agent. Redox Rep 8:272-275

28. Simonsen AC, Sørensen H (1999) Clinical tolerance of methylene blue virus-inactivated plasma. Vox Sang 77:210-217

29. Stevens S, Werner L, Mamalis N (2007) Corneal edema and permanent blue discoloration of a silicone intraocular lens by methylene blue. Ophthalmic Surg Lasers Imaging 38:136-141
30. Williamson LM, Cardigan R, Prowse CV (2003) Methylene bluetreated fresh-frozen plasma: what is its contribution to blood safety. Transfusion 43:1322-1329

31. Zoungrana A, Coulibaly B, Sié A, Walter-Sack I, Mockenhaupt FP, Kouyaté B, Schirmer RH, Klose C, Mansmann U, Meissner P, Mueller O (2008) Safety and efficacy of methylene blue combined with artesunate or amodiaquine for uncomplicated falciparum malaria: a randomized controlled trial from Burkina Faso. Available at: http://www.plosone.org/3:e1630

32. Zulian GB, Tullen E, Maton B (1995) Methylene blue for ifosfamide-associated encephalopathy. N Engl J Med 332:12391240 